\title{
Associations between dopamine D2 receptor gene polymorphisms and schizophrenia risk: a PRISMA compliant meta-analysis
}

This article was published in the following Dove Press journal:

Neuropsychiatric Disease and Treatment

9 December 2016

Number of times this article has been viewed

\author{
Hairong $\mathrm{He}^{\prime}$ \\ Huanhuan $\mathrm{Wu}^{1,2}$ \\ Lihong Yang' \\ Fan Gao' \\ Yajuan $\mathrm{Fan}^{3}$ \\ Junqin Feng ${ }^{3}$ \\ Xiancang $\mathrm{Ma}^{1,3}$ \\ 'Clinical Research Center, The First \\ Affiliated Hospital of Xi'an Jiaotong \\ University, ${ }^{2}$ College of Pharmacy, Xi'an \\ Medical University, ${ }^{3}$ Department of \\ Psychiatry, The First Affiliated Hospital \\ of Xi'an Jiaotong University, Xi'an, \\ Shaanxi, People's Republic of China
}

Correspondence: Xiancang Ma Department of Psychiatry, The First Affiliated Hospital of Xi'an Jiaotong University, 277 West Yanta Road,

Xi'an, Shaanxi 7I006I, People's

Republic of China

Tel +86 2985323614

Fax +862985323473

Email maxiancang@I63.com
Objective: To determine the relationships between dopamine D2 receptor gene polymorphisms and the risk of schizophrenia using meta-analysis.

Method: The PubMed, Embase, and China National Knowledge Infrastructure databases were searched to identify relevant literature published up to February 2016. The allele contrast model was used. Stata software was used for statistical analysis, with odds ratios (ORs) and 95\% confidence intervals (CIs) calculated to evaluate the associations between dopamine D2 receptor gene polymorphisms and the risk of schizophrenia. Meta-regression and publication bias, trim-and-fill, subgroup, sensitivity, cumulative, and fail-safe number analyses were also performed.

Results: This meta-analysis included 81 studies. The rs1801028 and rs1799732 were associated with schizophrenia risk among Asians $(P=0.04, \mathrm{OR}=1.25,95 \% \mathrm{CI}=1.01-1.55 ; P<0.01$, $\mathrm{OR}=0.76,95 \% \mathrm{CI}=0.63-0.92$, respectively), while the $\mathrm{rs} 6277$ was associated with schizophrenia risk in Caucasians $(P<0.01, \mathrm{OR}=0.72,95 \% \mathrm{CI}=0.66-0.79)$. The $\mathrm{rs} 1800497$ was also associated with schizophrenia risk in population-based controls $(P<0.01, \mathrm{OR}=0.84,95 \% \mathrm{CI}=0.72-0.97)$. The rs6275, rs 1079597, and rs1800498 were not associated with schizophrenia risk. In addition, meta-regression indicated that the controls may be sources of heterogeneity for the rs 1801028 single-nucleotide polymorphism (SNP), while ethnicity may be sources of heterogeneity for the rs6277 SNP. Publication bias was significant for the rs1801028 SNP, and this result changed after the publication bias was adjusted using the trim-and-fill method.

Conclusion: This meta-analysis demonstrated that the rs1801028 may be a risk factor for susceptibility to schizophrenia among Asians, while the rs 1799732 may be a protective factor for that population. Large-sample studies are necessary to verify the results of this meta-analysis Keywords: dopamine D2 receptor, polymorphisms, schizophrenia

\section{Introduction}

Schizophrenia is a severe mental disorder characterized by changes in its higher functions and deterioration of behavior, cognition, emotions, motivation, and perception, and is marked by socio-occupational dysfunction. Schizophrenia manifests with a wide variety of positive (auditory hallucinations and paranoid delusions), negative (affective flattening, anhedonia, and alogia), and cognitive (declined attention and memory) symptoms. ${ }^{1}$ It is a complex multifactorial psychiatry disorder involving genetic and environmental factors, with a global lifetime prevalence of $0.5 \%-1 \%{ }^{2}$

Family, twin, and adoption studies have shown that genetic factors play a significant role in the pathogenesis of schizophrenia, with the heritability of schizophrenia being estimated at $70 \%-80 \%{ }^{3,4}$ Additionally, Lee et al estimated that $23 \%$ of variation in 
liability to schizophrenia is captured by single-nucleotide polymorphisms (SNPs). ${ }^{5}$ For schizophrenia, some genetic factors were shared with other psychiatric disorders (bipolar disorder, major depressive disorder, autism spectrum disorders, and attention-deficit/hyperactivity disorder), ${ }^{6}$ and some genetic factors associated with its risk were overlapped with those associated with reproduction traits (eg, age at first birth). ${ }^{7}$ In short, schizophrenia is highly polygenic. ${ }^{8}$

The dopamine hypothesis is one of the main ideas for explaining the etiology of schizophrenia. ${ }^{9}$ There are several lines of evidence implicating dopamine D2 receptor (DRD2) as the main candidate gene for the risk of schizophrenia. ${ }^{10}$ In humans, the DRD2 gene is located on chromosome 11 at q22-q23, extends over $270 \mathrm{~kb}$, and has eight exons. ${ }^{11}$ Associations between schizophrenia risk and four SNPs have been widely studied: rs1799732 (-141C Ins/Del), rs1801028 (311 Ser/Cys), rs 1800497 (TaqIA), and rs6277 (C957T). ${ }^{12,13}$ The rs1799732 SNP is located in the DRD2 promoter region and has been demonstrated to affect gene expression in vitro. ${ }^{14}$ The rs $1801028 \mathrm{SNP}$ is the missense variant $960 \mathrm{C} / \mathrm{G}$ in exon 7 of the DRD2 gene ${ }^{15}$ that can alter the physiology and function of the D2 receptor. ${ }^{12}$ The rs1800497 SNP was previously thought to be located in the DRD2 3'-untranslated region and was recently identified as being in exon 8 of the ankyrin repeat and kinase domain containing 1 (ANKK1) gene. This SNP has been considered to alter substrate-binding specificity. ${ }^{16}$ The rs6277 SNP is located in exon 7 of the $D R D 2$ gene and alters mRNA folding, leading to a decrease in mRNA stability and translation, and markedly changing dopamine-induced up-regulation of DRD2 expression. ${ }^{17}$ In addition, associations between schizophrenia risk and the rs6275 (C939T), rs1079597 (TaqIB), and rs1800498 (TaqID) SNPs have been widely reported. ${ }^{18,19}$

While associations between $D R D 2$ gene polymorphisms and the risk of schizophrenia have been studied extensively, there are still some uncertainties about these associations. The present meta-analysis was therefore performed to further identify the associations between $D R D 2$ gene polymorphisms and schizophrenia risk. Meta-regression and publication bias, nonparametric trim-and-fill, subgroup, sensitivity, cumulative, and fail-safe number analyses were also performed.

\section{Method}

\section{Search strategy}

The PubMed, Embase, and China National Knowledge Infrastructure databases were independently searched by two reviewers ( $\mathrm{He}$ and $\mathrm{Wu}$ ) to collect the literature related to associations between DRD2 gene polymorphisms and schizophrenia risk. The last search update was performed in February 2016, and the following keywords were used in the literature search: "schizophrenia", "psychosis", "schizophrenic," "DRD2," "dopamine receptor 2," "dopamine receptor D2", “dopamine D2 receptor", "polymorphism”, "variant", "variation", "allele", and "genotype". The species was limited to human. Moreover, the literature references in all of the included documents were searched to find more studies that were consistent with the eligibility criteria.

\section{Eligibility criteria}

1. Studies that met the following inclusion criteria were included:

a) Research study with a case-control design.

b) Written in Chinese or English.

c) Investigation of the associations between $D R D 2$ gene polymorphisms and the risk of schizophrenia.

d) Providing sufficient allele or genotype distribution data of the included cases and controls.

2. Studies that met any of the following exclusion criteria were excluded:

a) Repetition of information in other literature.

b) A review, comment, or conference proceedings.

c) Results obtained in an animal model.

d) Series of reports or case reports.

\section{Research screening}

The studies were first screened by browsing the titles and abstracts of the identified documents. Secondary screening was then performed by reading the full text of selected reports. Finally, data extraction and quality assessment were performed for the included studies.

\section{Data extraction}

In our present study, two reviewers ( $\mathrm{He}$ and $\mathrm{Wu}$ ) independently extracted the following information from the included literature: first author, publication year, mean age of the cases and controls, country, ethnicity, source of controls, numbers of cases and controls, DRD2 gene locus, diagnostic criteria of schizophrenia, genotyping method, and conformity with Hardy-Weinberg equilibrium (HWE) for the controls. If the allele or genotype distribution data of the cases and controls were not reported in the original articles, the corresponding author was contacted by mail to obtain this information.

\section{Quality assessment}

Two authors ( $\mathrm{HH}$ and $\mathrm{HW}$ ) independently performed quality assessment using quality scoring criteria ${ }^{20}$ based on criteria previously applied in observational studies for addressing genetic epidemiological issues, with the scores ranging from 
0 points (worst) to 9 points (best) (Table S1). A study was classified as being of low quality when it scored $<6$ points. Sensitivity analysis was conducted by deleting these lowquality studies.

\section{Statistical analysis}

Odds ratios (ORs) and 95\% confidence intervals (CIs) were used to evaluate the strengths of the associations between DRD2 gene polymorphisms and schizophrenia risk. Pooled effect sizes were calculated using the random-effects model. This model evaluated different underlying influences considering both within- and between-study variations, which provided the advantage of accommodating diversity between studies and yielding a more conservative estimate of the assessed effect. ${ }^{21}$ The present study used an allele comparison model because this maximized the number of included studies.

Cochran's $Q$ statistic was used to estimate the degree of heterogeneity in the included studies. Heterogeneity was considered to be high when the $P$-value was $<0.1$. The heterogeneity was also quantified using the $I^{2}$ statistic and was considered high when $I^{2}>50 \%$. Based on clinical knowledge, the ethnicity and source of controls were considered to be responsible for heterogeneity, and so these parameters were set as covariates in the meta-regression. A subgroup analysis was also conducted.
Publication bias was analyzed using Begg's funnel plots. An asymmetrical funnel plot indicated the presence of significant publication bias. The symmetry of Begg's funnel plots was judged using Egger's linear regression, and a $P$-value of $<0.05$ was considered to indicate that the funnel plots were significantly asymmetrical. The trim-and-fill method was used to correct for publication bias and also to assess the impact of publication bias on the results.

Sensitivity analysis was used to assess both the potential impact of single studies on the pooled effect size and the impact of removing low-quality studies on the obtained results. Cumulative analysis by publication year was used to explore temporal trends in the results. Finally, the fail-safe number of negative studies that would be required to nullify (ie, make $P>0.05$ ) the effect size was calculated.

All of the statistical analyses were conducted using Stata software, version 12.0 (Stata Corporation, College Station, TX, USA).

\section{Results}

\section{Study characteristics}

A flow chart of the study selection procedure is shown in Figure 1. Briefly, 1,267 studies were identified after eliminating 304 duplications. After reviewing the abstracts or reading full texts carefully according to eligibility criteria,



Figure I Flow diagram of the study selection process.

Abbreviations: CNKI, China National Knowledge Infrastructure; DRD2, dopamine D2 receptor. 
a further 1,186 studies were excluded. Finally, 81 studies were identified for exploring the associations between $D R D 2$ gene polymorphisms and susceptibility to schizophrenia in a meta-analysis.

The main features of the included studies are listed in Table 1. The 81 studies comprised 45 studies focused on Caucasians, 34 on Asians, and 2 on mixed populations. The distributions of genotypes in the control groups deviated from HWE for the rs1801028, rs1800497, and rs1800498 SNPs in seven studies. ${ }^{11,22-27}$ The quality assessment revealed that four studies were of low quality. ${ }^{26,28-30}$

\section{Association between the rs 1801028 (3II Ser/Cys) and schizophrenia risk}

A meta-analysis of 42 case-control studies $(9,771$ cases and 11,900 controls) revealed that the variant allele $\mathrm{G}$ (Cys) was associated with increased schizophrenia risk in all populations $(P=0.009, \mathrm{OR}=1.23,95 \% \mathrm{CI}=1.05-1.44$; Figure $2 \mathrm{~A})$. The fail-safe number was 104.52, and there was moderate heterogeneity $\left(I^{2}=35 \%\right)$. Meta-regression indicated that the source of controls may have been responsible for this heterogeneity $(P<0.01)$. The subgroup analysis, whose results are presented in Table 2, revealed that the G allele was associated with increased susceptibility to schizophrenia in Asians $(P=0.04, \mathrm{OR}=1.25,95 \% \mathrm{CI}=1.01-1.55)$ and hospital-based controls $(P<0.01, \mathrm{OR}=1.91,95 \% \mathrm{CI}=1.39-2.61)$.

Sensitivity analysis indicated that no single study qualitatively changed the pooled ORs (Figure 3 ). Removing the low-quality studies ${ }^{26,29,30}$ did not change the results. Four of the studies deviated from HWE, 22,24,26,27 but removing them from the analysis did not change the results. Cumulative analysis by publication year confirmed that pooled ORs and 95\% CIs were stable and that there was a reliable temporal trend in the results from $1996^{31}$ (Figure 4).

In terms of publication bias, Egger's linear regression showed that the funnel plots were asymmetrical $(P=0.023)$. The trim-and-fill method suggested that eight studies were missing, and the results for the association between the rs1801028 SNP and schizophrenia changed after replacing the data for these eight studies (OR $=1.063,95 \%$ $\mathrm{CI}=0.892-1.266$; Figure 5). This indicates that our analyses were not stable and that future research is very likely to produce different results.

\section{Association between the rs6277 (C957T) and schizophrenia risk}

A meta-analysis of 12 case-control studies (2,919 cases and 3,600 controls) revealed that the variant allele $\mathrm{T}$ was associated with decreased schizophrenia risk $(P=0.002$, $\mathrm{OR}=0.80,95 \% \mathrm{CI}=0.69-0.92$; Figure 2B). The failsafe number was 91.00, there was high heterogeneity $\left(I^{2}=58.5 \%\right)$, and meta-regression indicated that ethnicity may have been responsible for this heterogeneity $(P<0.01)$. A subgroup analysis based on ethnicity showed that the $\mathrm{T}$ allele was associated with decreased susceptibility to schizophrenia in Caucasians $(P<0.01$, OR $=0.72,95 \%$ $\mathrm{CI}=0.66-0.79$ ).

Cumulative analysis by publication year did not show a reliable temporal trend. Sensitivity analysis showed that no single study qualitatively changed the pooled ORs. In terms of publication bias, Egger's linear regression showed that the funnel plots were symmetrical $(P=0.119)$.

\section{Association between the rs 1799732 (-I4IC Ins/Del) and schizophrenia risk}

A meta-analysis of 27 case-control studies $(6,770$ cases and 7,347 controls) demonstrated that the rs1799732 SNP was not associated with schizophrenia risk $(P=0.26, \mathrm{OR}=0.91$, $95 \% \mathrm{CI}=0.78-1.07$; Figure $2 \mathrm{C}$ ). There was high heterogeneity $\left(I^{2}=76 \%\right)$, and meta-regression indicated that neither ethnicity $(P=0.119)$ nor the source of controls $(P=0.452)$ was responsible for this heterogeneity. A subgroup analysis based on ethnicity showed that the variant type $(-141 \mathrm{C}$ Del) was associated with decreased susceptibility to schizophrenia in Asians $(P=0.004, \mathrm{OR}=0.76,95 \%$ $\mathrm{CI}=0.63-0.92$ ). A subgroup analysis based on the source of controls found no significant association between the rs1799732 SNP and schizophrenia risk in population-based controls or hospital-based controls. In terms of publication bias, Egger's linear regression showed that the funnel plots were symmetrical $(P=0.173)$.

\section{Association between the rs 1800497 (TaqlA) and schizophrenia risk}

A meta-analysis of 22 case-control studies (4,017 cases and 4,209 controls) demonstrated that the rs 1800497 SNP was not associated with schizophrenia risk $(P=0.06, \mathrm{OR}=0.87,95 \%$ $\mathrm{CI}=0.75-1.01$; Figure 2D). There was high heterogeneity $\left(I^{2}=72 \%\right)$, and meta-regression indicated that neither ethnicity $(P=0.612)$ nor the source of controls $(P=0.372)$ was responsible for this heterogeneity. A subgroup analysis based on the source of controls revealed that the variant allele A (A2) was associated with decreased schizophrenia risk in populationbased controls $(P<0.01$, OR $=0.84,95 \% \mathrm{CI}=0.72-0.97)$. A subgroup analysis based on ethnicity revealed that the rs 1800497 SNP was also not associated with susceptibility to 


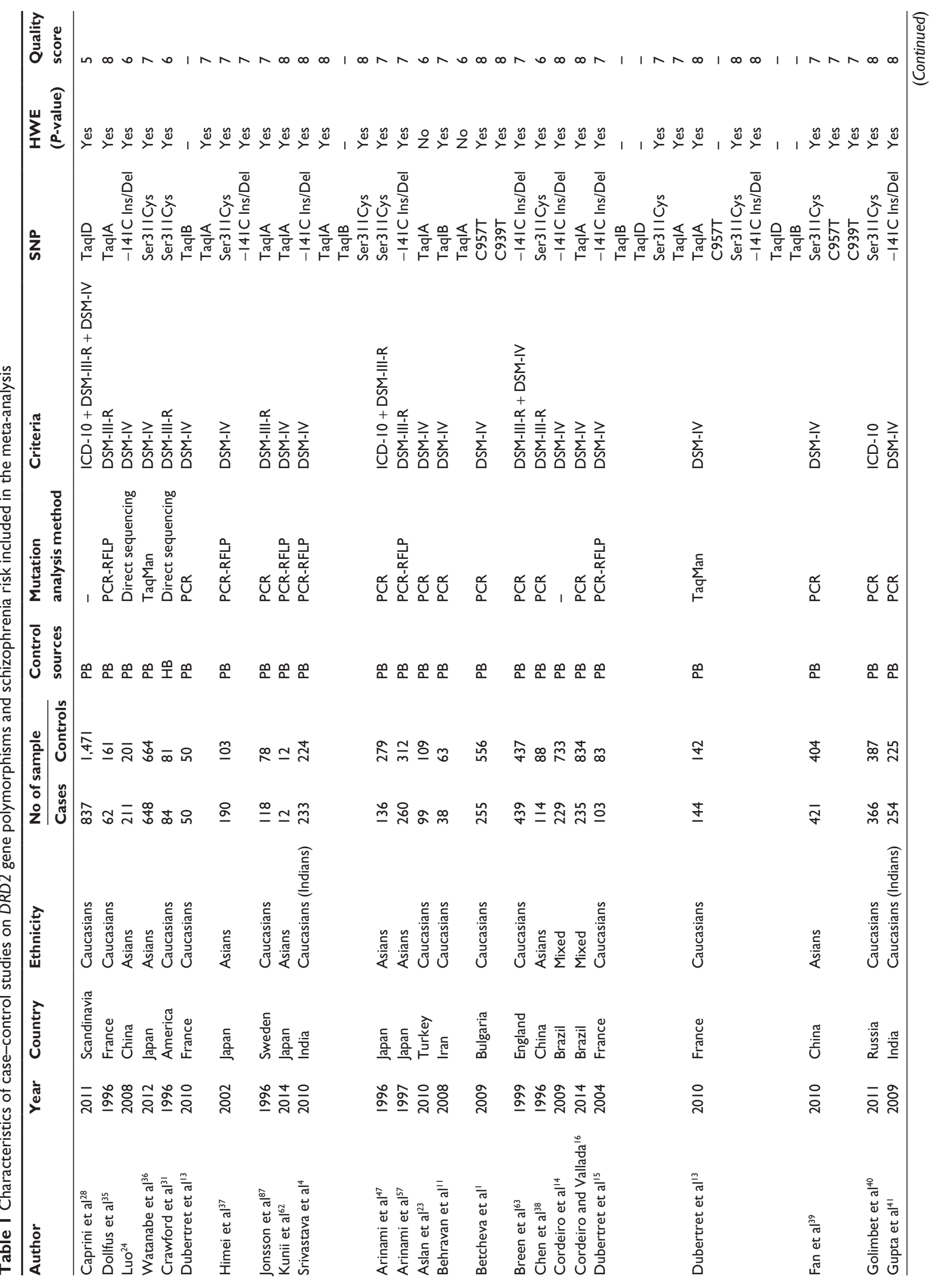




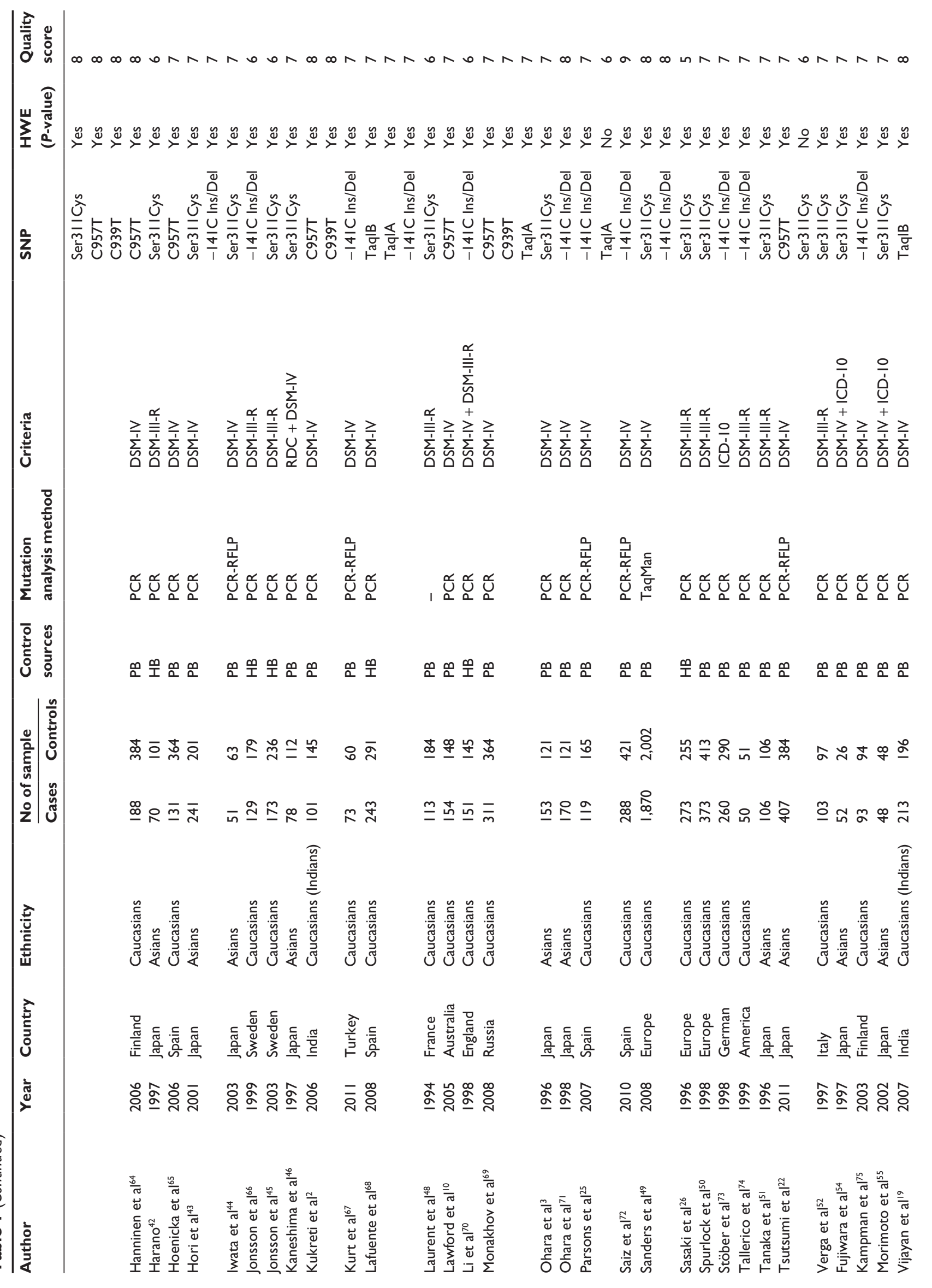




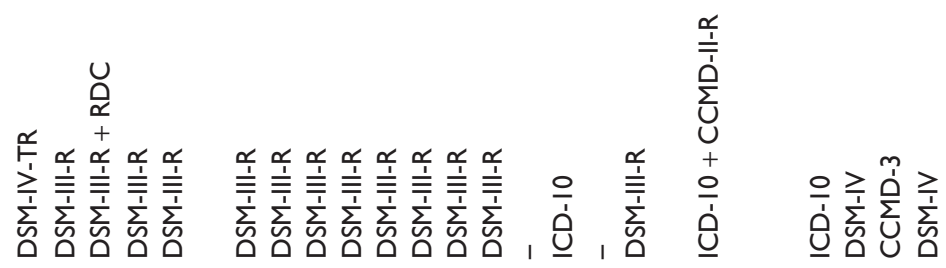

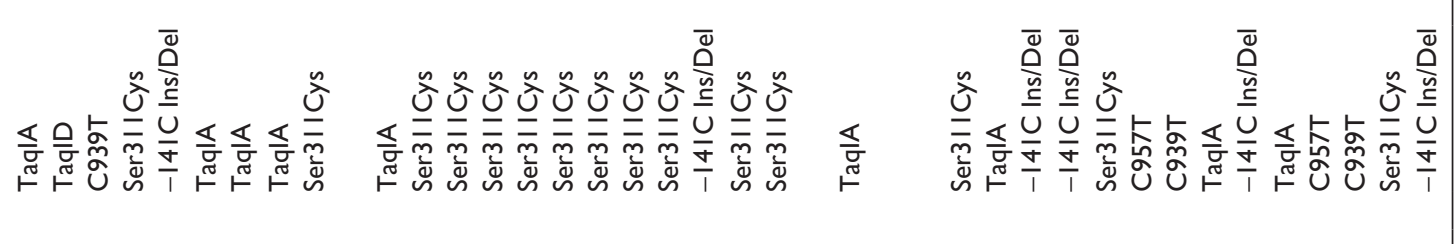

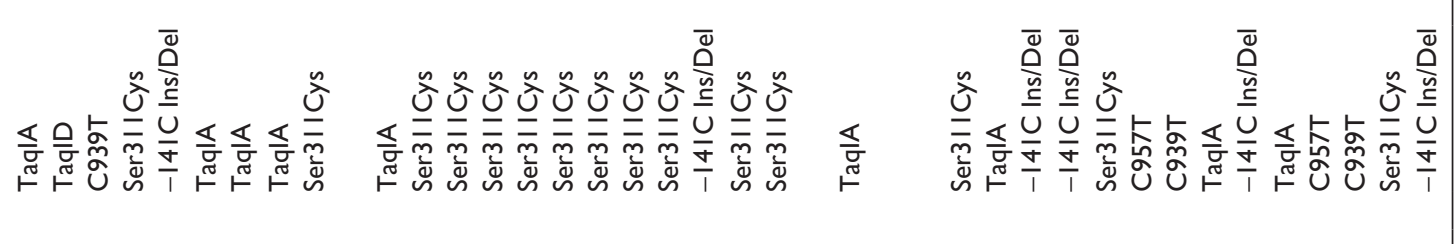

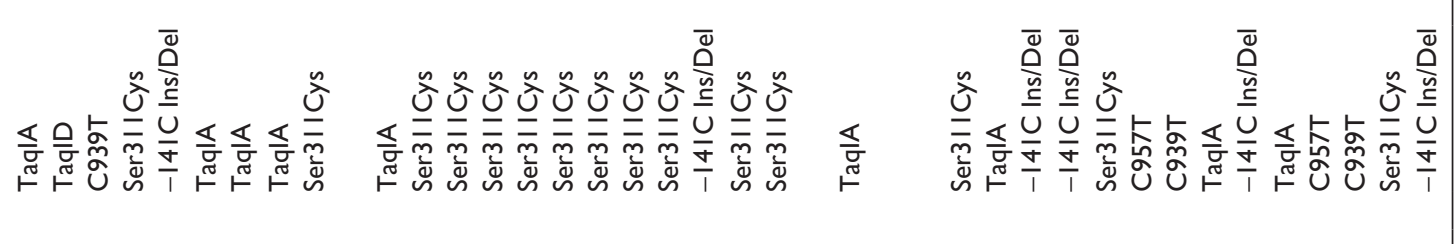

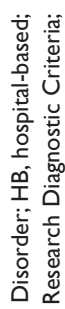

ن

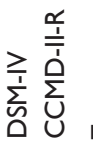

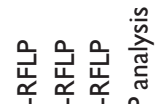



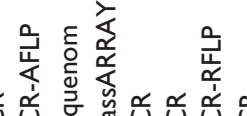

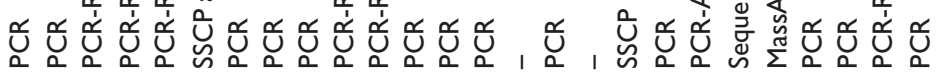

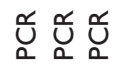

Ư⿱宀口

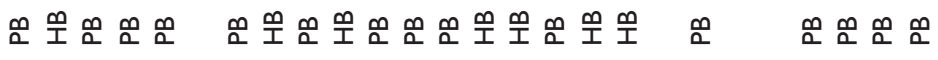

$\cong \unrhd$



응ํํㅡㅇ 은

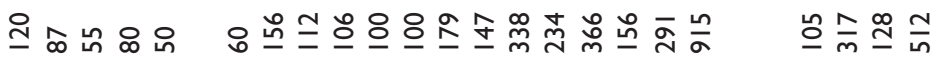

ํํำำ

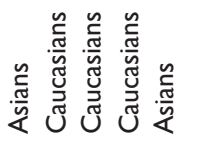

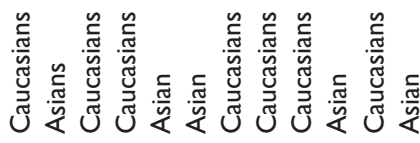

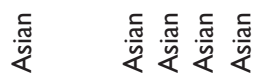

貿其

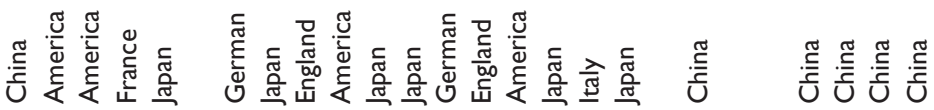

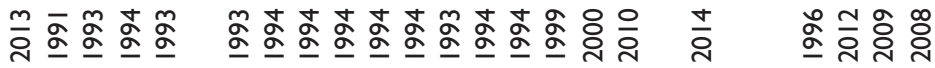

突

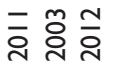

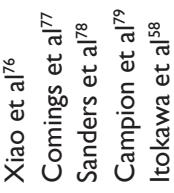

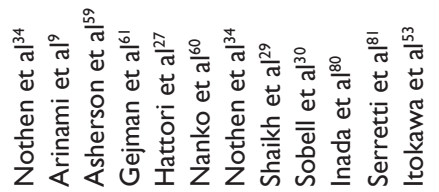

๓ّ

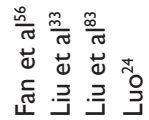

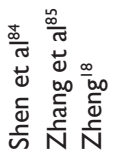

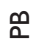

츨

है छั

苞 

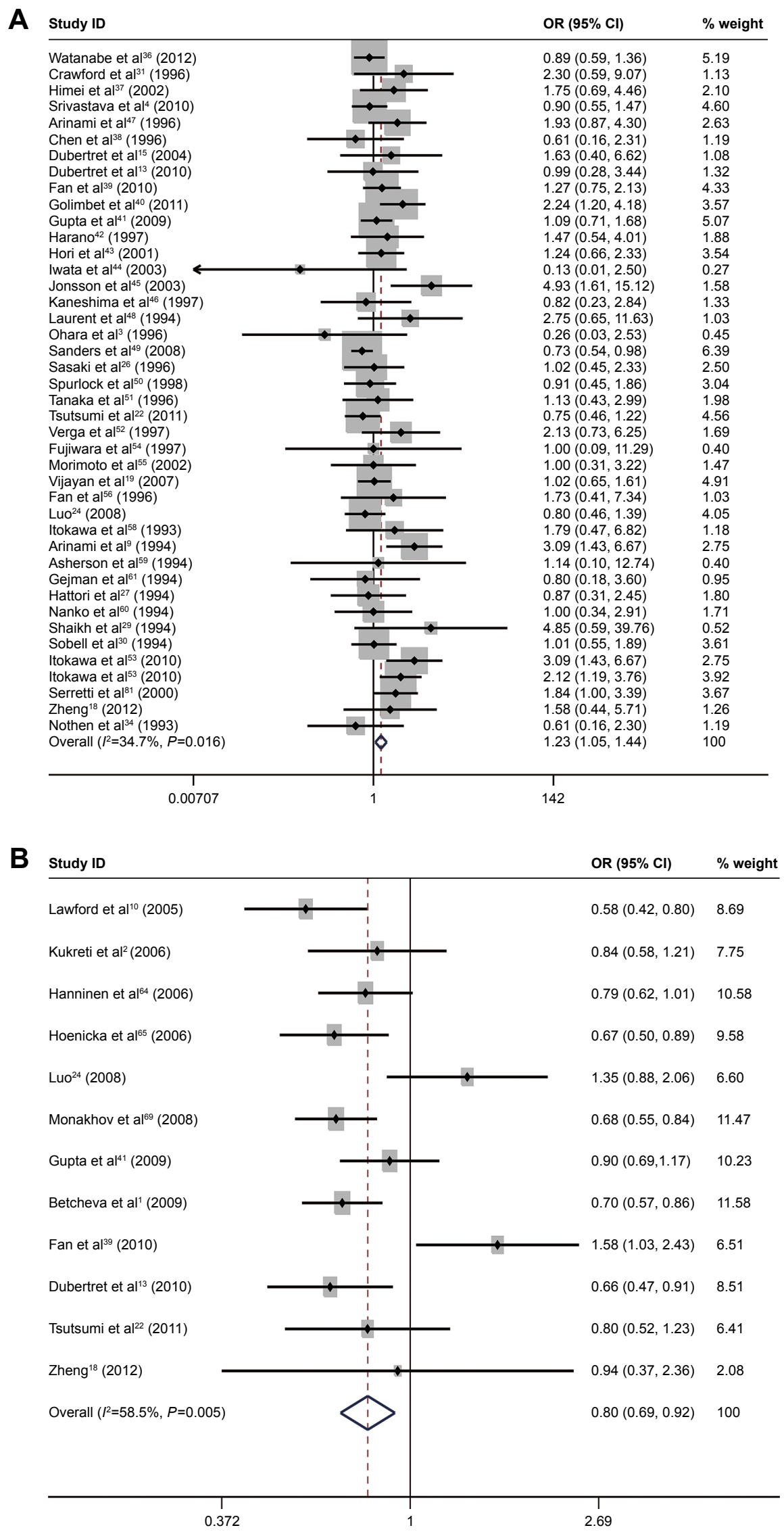

Figure 2 (Continued) 


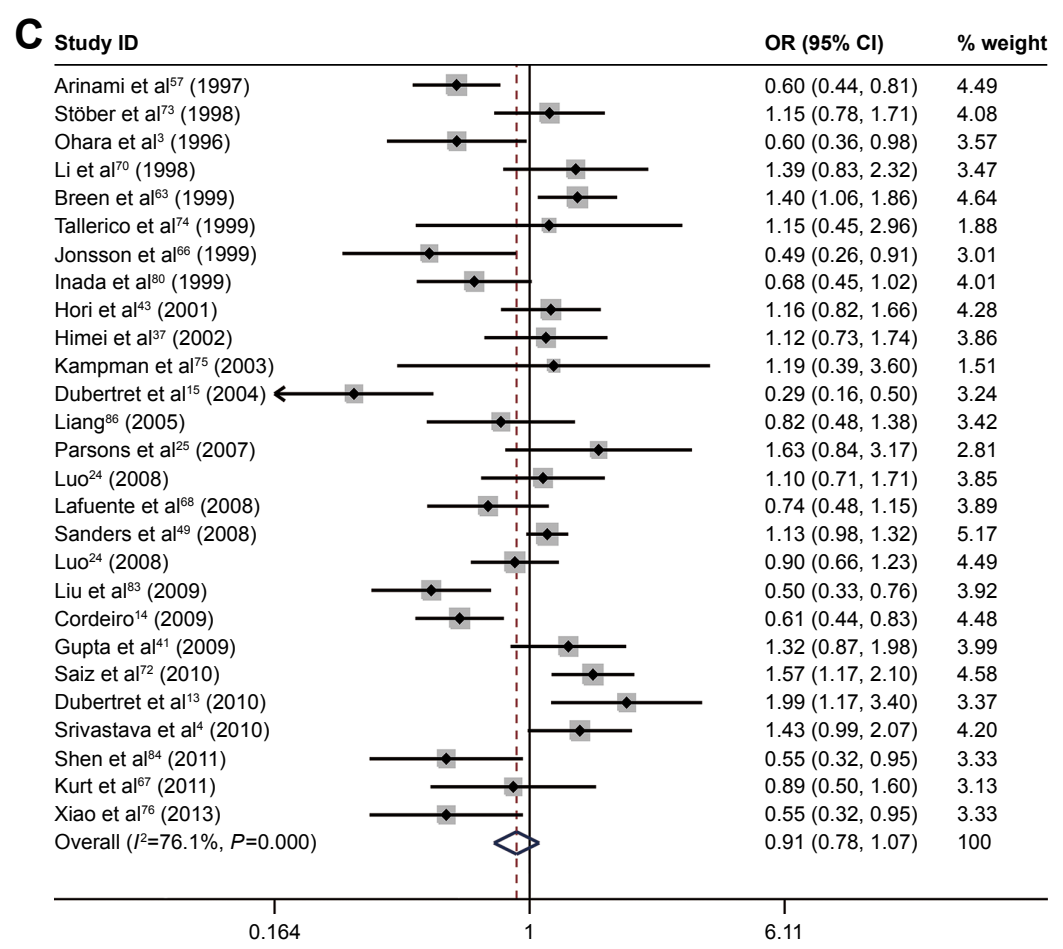

$\mathbf{D}$



Figure 2 Calculated $\mathrm{OR}$ and $95 \% \mathrm{Cl}$ for the associations between DRD2 gene polymorphism and schizophrenia risk.

Notes: (A) rs I801028; (B) rs6277; (C) rs 1799732; (D) rs 1800497. weights are from random effects analysis.

Abbreviations: $\mathrm{Cl}$, confidence interval; DRD2, dopamine D2 receptor; OR, odds ratio.

schizophrenia. There were four studies of the rs 1800497 SNP that included controls that did not conform with HWE, but they did not influence the results. ${ }^{11,23-25}$ In terms of publication bias, Egger's linear regression showed that the funnel plots were symmetrical $(P=0.861)$.

\section{Association between the other SNPs and schizophrenia risk}

There was no evidence that the susceptibility to schizophrenia was associated with the rs 6275 ( $\mathrm{T}$ vs $\mathrm{C}, P=0.10, \mathrm{OR}=0.92,95 \%$ $\mathrm{CI}=0.83-1.02$ ), $\mathrm{rs} 1079597$ ( $\mathrm{T}$ vs $\mathrm{C}, P=0.12, \mathrm{OR}=0.72,95 \%$ 
Table 2 Subgroup analysis of case-control studies on DRD2 gene polymorphisms and schizophrenia risk

\begin{tabular}{|c|c|c|c|c|c|c|c|}
\hline SNP & Subgroup type & Subgroup & $\mathbf{N}$ & $P$-value & OR & $95 \% \mathrm{Cl}$ & $I^{2}(\%)$ \\
\hline \multirow[t]{4}{*}{ rs 1801028} & Control sources & Population-based & 31 & 0.99 & 1.00 & $0.88, I .14$ & 0 \\
\hline & & Hospital-based & II & $<0.01$ & 1.91 & $1.39,2.6 \mid$ & 31 \\
\hline & Ethnicity & Caucasians & 19 & 0.09 & 1.22 & $0.97,1.54$ & 41 \\
\hline & & Asians & 23 & 0.04 & 1.25 & I.0I, 1.55 & 31 \\
\hline \multirow[t]{2}{*}{ rs6277 } & Ethnicity & Caucasians & 8 & $<0.01$ & 0.72 & $0.66,0.79$ & 0 \\
\hline & & Asians & 4 & 0.37 & 1.17 & $0.83,1.64$ & 46 \\
\hline \multirow[t]{5}{*}{ rsI799732 } & Control sources & Population-based & 24 & 0.36 & 0.92 & $0.78,1.10$ & 77 \\
\hline & & Hospital-based & 3 & 0.46 & 0.81 & $0.47,1.4 \mathrm{I}$ & 71 \\
\hline & Ethnicity & Caucasians & 15 & 0.33 & 1.11 & $0.90,1.36$ & 7I \\
\hline & & Asians & 11 & 0.004 & 0.76 & $0.63,0.92$ & 56 \\
\hline & & Mixed & I & 0.002 & 0.61 & $0.44,0.83$ & - \\
\hline \multirow[t]{5}{*}{ rsI800497 } & Control sources & Population-based & 20 & 0.02 & 0.84 & $0.72,0.97$ & 71 \\
\hline & & Hospital-based & 2 & 0.46 & 1.50 & $0.5 \mathrm{I}, 4.47$ & 86 \\
\hline & Ethnicity & Caucasians & 16 & 0.24 & 0.88 & $0.72,1.08$ & 71 \\
\hline & & Asians & 5 & 0.29 & 0.85 & $0.63,1.15$ & 82 \\
\hline & & Mixed & I & 0.06 & 0.82 & $0.66,1.01$ & - \\
\hline
\end{tabular}

Abbreviations: $\mathrm{Cl}$, confidence intervals; DRD2, dopamine D2 receptor; OR, odds ratios; SNP, single-nucleotide polymorphisms.

\section{Meta-analysis estimates, given named study is omitted}

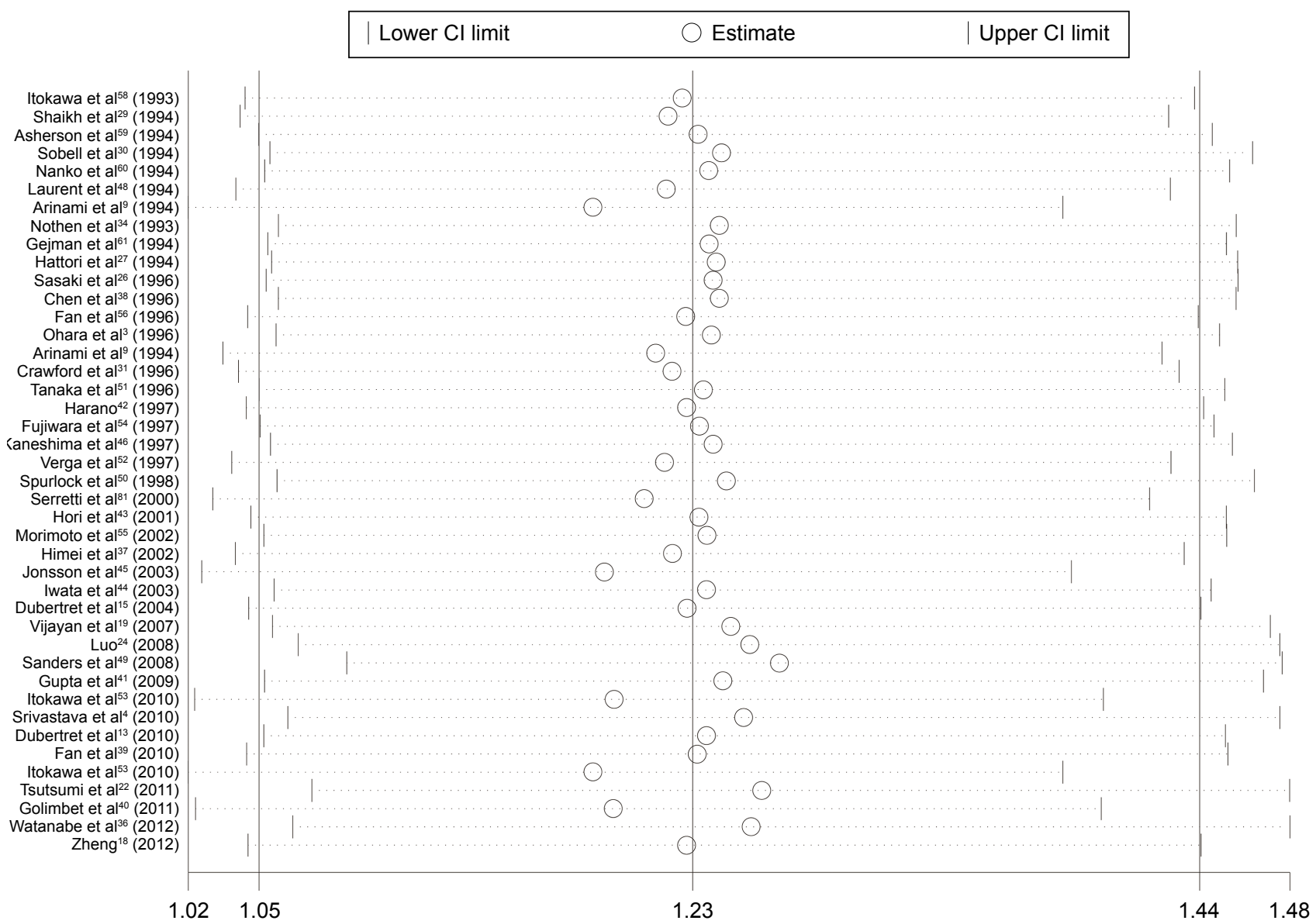

Figure 3 Sensitivity analysis via deletion of each individual study reflecting the relative influence of each individual dataset on the pooled ORs for the rs 180 I028. Abbreviations: $\mathrm{Cl}$, confidence interval; OR, odds ratio. 


\section{Study ID}

Itokawa et $a^{58}$ (1993)

Shaikh et al ${ }^{29}$ (1994)

Asherson et al ${ }^{59}$ (1994)

Sobell et $\mathrm{al}^{30}$ (1994)

Nanko et al ${ }^{60}(1994)$

Laurent et al ${ }^{48}$ (1994)

Arinami et al ${ }^{9}$ (1994)

Nothen et al ${ }^{34}$ (1993)

Gejman et al ${ }^{61}$ (1994)

Hattori et al ${ }^{27}$ (1994)

Sasaki et al ${ }^{26}$ (1996)

Chen et $\mathrm{al}^{38}$ (1996)

Fan et al ${ }^{56}$ (1996)

Ohara et $\mathrm{al}^{3}$ (1996)

Arinami et $\mathrm{al}^{9}$ (1994)

Crawford et $\mathrm{al}^{31}$ (1996)

Tanaka et al ${ }^{51}$ (1996)

Harano $^{42}$ (1997)

Fujiwara et al ${ }^{54}$ (1997)

Kaneshima et $\mathrm{al}^{46}$ (1997)

Verga et al ${ }^{52}$ (1997)

Spurlock et al ${ }^{50}$ (1998)

Serretti et al ${ }^{81}$ (2000)

Hori et al ${ }^{43}$ (2001)

Morimoto et $\mathrm{al}^{55}$ (2002)

Himei et al ${ }^{37}$ (2002)

Jonsson et al ${ }^{45}$ (2003)

Iwata et $\mathrm{al}^{44}$ (2003)

Dubertret et $\mathrm{al}^{15}$ (2004)

Vijayan et al19 (2007)

$\operatorname{Luo}^{24}$ (2008)

Sanders et al ${ }^{49}$ (2008)

Gupta et al ${ }^{41}$ (2009)

Itokawa et $\mathrm{al}^{53}$ (2010)

Srivastava et $\mathrm{al}^{4}$ (2010)

Dubertret et $\mathrm{al}^{13}$ (2010)

Fan et al ${ }^{39}$ (2010)

Itokawa et $\mathrm{al}^{53}$ (2010)

Tsutsumi et al ${ }^{22}$ (2011)

Golimbet et $\mathrm{al}^{40}$ (2011)

Watanabe et al ${ }^{36}$ (2012)

Zheng $^{18}$ (2012)
OR $(95 \% \mathrm{Cl})$

$1.79(0.47,6.82)$

$2.39(0.77,7.37)$

$2.09(0.75,5.81)$

$1.23(0.73,2.09)$

$1.18(0.74,1.90)$

$1.28(0.82,2.02)$

$1.67(1.05,2.65)$

$1.52(0.96,2.42)$

$1.45(0.94,2.23)$

$1.36(0.92,2.02)$

$1.31(0.93,1.84)$

$1.25(0.90,1.74)$

$1.27(0.93,1.73)$

$1.23(0.89,1.70)$

$1.30(0.96,1.75)$

$1.33(1.00,1.78)$

$1.32(1.01,1.72)$

$1.33(1.03,1.71)$

$1.32(1.03,1.70)$

$1.30(1.01,1.66)$

$1.33(1.04,1.70)$

$1.28(1.02,1.61)$

$1.34(1.08,1.66)$

$1.33(1.08,1.63)$

$1.32(1.08,1.61)$

$1.33(1.10,1.62)$

$1.39(1.14,1.68)$

$1.37(1.13,1.67)$

$1.38(1.14,1.67)$

$1.32(1.10,1.57)$

$1.27(1.06,1.51)$

$1.21(1.00,1.46)$

$1.19(1.00,1.42)$

$1.24(1.03,1.48)$

$1.21(1.02,1.44)$

$1.20(1.02,1.42)$

$1.20(1.03,1.41)$

$1.25(1.06,1.48)$

$1.22(1.04,1.44)$

$1.25(1.06,1.48)$

$1.23(1.05,1.44)$

$1.23(1.05,1.44)$

\begin{tabular}{c|c|c}
\hline & & 1 \\
0.136 & 1 & 7.37
\end{tabular}

Figure 4 Cumulative meta-analyses according to publication year for the rs 1801028. 


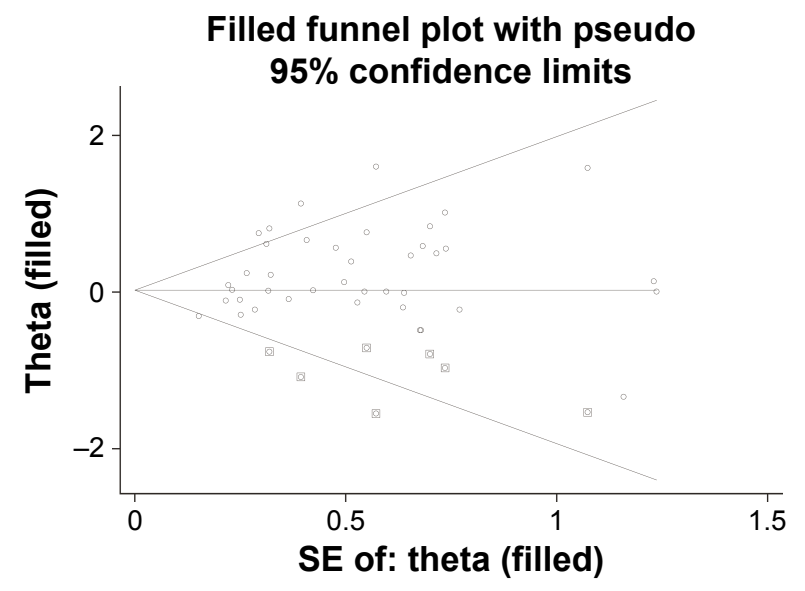

Figure 5 Trim-and-fill plot to correct publication bias for the rs 1801028 . Abbreviation: SE, standard error.

$\mathrm{CI}=0.47-1.10$ ), or rs 1800498 ( $\mathrm{T}$ vs $\mathrm{C}, P=0.52$, OR $=1.03$, $95 \% \mathrm{CI}=0.93-1.15)$ SNP. Sensitivity analysis indicated that no single study of the rs 1800498 SNP qualitatively changed the pooled ORs. Removing the low-quality study ${ }^{28}$ did not change the result.

\section{Discussion}

A comprehensive analysis about schizophrenia-associated genetic loci had been performed in a genome-wide association study. ${ }^{32}$ Our meta-analysis results provide evidence that the rs1801028 and rs6277 SNPs are associated with the risk of schizophrenia. A subgroup analysis indicated that the rs1801028 SNP may increase the risk of schizophrenia in Asians and hospital-based controls, the rs6277 SNP may reduce the risk of schizophrenia in Caucasians, the rs 1799732 SNP may reduce the risk of schizophrenia in Asians, and the rs1800497 SNP may reduce the risk of schizophrenia in population-based controls.

Yao et al performed a similar study of the associations between $D R D 2$ gene polymorphisms and schizophrenia risk. ${ }^{12}$ That study used a genetic model, while our study used an allele contrast model since this made it possible to include the largest number of documents and the maximum sample sizes. Other advantages of the present study were 1) the inclusion of more published documents (including those written in Chinese), which increased the statistical power of our results, 2) more SNPs being investigated, and 3 ) the application of meta-regression and publication bias, nonparametric trim-and-fill, subgroup, sensitivity, cumulative, and fail-safe number analysis also being performed.

The results of the present study show that the rs 1801028 SNP may increase the risk of schizophrenia in Asians and hospital-based controls. Yao et al reported the same result under the dominant model. ${ }^{12}$ Different results may be obtained for different races due to differences in genetic backgrounds and living conditions. ${ }^{33}$ Moreover, the results for the subgroup analysis based on hospital-based controls are not reliable because such controls may not be representative and samples of hospital-based controls are often too small, and so these results should be treated cautiously. The results for publication bias were significant, and these changed after being adjusted using the trim-and-fill method, which indicated that those results may not be very stable. This means that if new articles are published in the future, the results of a complete meta-analysis including all available data are very likely to change. The presence of significant publication bias was probably due to our meta-analysis including many smallsample studies. Yao et al found only slight publication bias, but this was not corrected using the trim-and-fill method. ${ }^{12}$

Twelve of the included documents related to the rs6277 SNP and the meta-analysis showed that this SNP may reduce the risk of schizophrenia in Caucasians; however, Yao et al did not study this SNP. ${ }^{12}$ However, our included samples for this SNP were small and the cumulative analysis by publication year did not show a reliable trend. This means that the statistical power of the results may not have been high.

In our meta-analysis the rs1799732 SNP was not associated with schizophrenia risk, and Yao et al obtained the same result under the dominant model. ${ }^{12}$ After performing subgroup analysis, the current meta-analysis indicated that the rs1799732 SNP might reduce the risk of schizophrenia in Asians. In contrast, Yao et al did not find any correlation between the rs1799732 SNP and schizophrenia risk in different races and different populations. The possible reasons for different conclusions being drawn based on the current and previous meta-analyses of the rs1799732 SNP are 1) more documents being included in the present study, especially the Chinese literature, because this is likely to have greatly increased the sample size for Asians, and 2) the use of different genetic models.

The previous meta-analyses did not explore the correlations between the rs1800497 SNP and schizophrenia risk in all populations. After performing subgroup analysis, the present study found that the rs 1800497 SNP was associated with schizophrenia risk in population-based controls. In contrast, Yao et al found that the rs 1800497 SNP may increase the risk of schizophrenia in Caucasians. ${ }^{12}$ The possible reasons for the current and previous meta-analyses drawing different conclusions from their subgroup analyses of the rs1800497 SNP are 1) Yao et al applying the wrong allele or genotype distribution data of cases and controls regarding the study of Nothen et al; $; 2$ 2) the smallness of the study sample of Yao et al; 3) that study not including Chinese studies; and 
4) our use of different genetic models. These factors mean that the statistical power would have been higher for the present study.

It is important to note the limitations of our metaanalysis. 1) Meaningless or negative results might not be published, which would lead to some degree of publication bias. 2) Schizophrenia is a multifactorial disease, whereas the present study only considered the impact of the DRD2 gene on schizophrenia risk, and also ignored the possible impacts of environmental factors, age, gender, lifestyle, and diagnosis standards.

In conclusion, this meta-analysis has shown that the rs1801028 SNP may be a risk factor for susceptibility to schizophrenia in Asians, the rs6277 SNP may be a protective factor for susceptibility to schizophrenia in Caucasians, and the rs1799732 SNP may be a protective factor for susceptibility to schizophrenia in Asians. However, the occurrence of schizophrenia represents the cumulative effect of multiple genes, and so only studying a single gene or single polymorphism is unlikely to be adequate. Future studies should pay more attention to the interactions within and between genes as well as within and between their polymorphisms in order to better explain the genetic mechanisms underlying mental illness.

\section{Acknowledgment}

This work was supported by the National Natural Science Foundation of China (No 81471374).

\section{Author contributions}

$\mathrm{HRH}$ and $\mathrm{HHW}$ performed literature research, data extraction, statistical analysis, and data interpretation. XCM contributed to the study concept and study design. LHY and FG contributed to make figures and tables. YJF and JGF were responsible for the quality control of data and algorithms. All authors contributed toward data analysis, drafting and revising the paper and agree to be accountable for all aspects of the work.

\section{Disclosure}

The authors report no conflicts of interest in this work.

\section{References}

1. Betcheva ET, Mushiroda T, Takahashi A, et al. Case-control association study of 59 candidate genes reveals the DRD2 SNP rs6277 (C957T) as the only susceptibility factor for schizophrenia in the Bulgarian population. J Hum Genet. 2009;54(2):98-107.

2. Kukreti R, Tripathi S, Bhatnagar P, et al. Association of DRD2 gene variant with schizophrenia. Neurosci Lett. 2006;392(1-2):68-71.

3. Ohara K, Nakamura Y, Xie DW, et al. Polymorphisms of dopamine D2-like (D2, D3, and D4) receptors in schizophrenia. Biol Psychiatry. 1996;40(12):1209-1217.
4. Srivastava V, Deshpande SN, Thelma BK. Dopaminergic pathway gene polymorphisms and genetic susceptibility to schizophrenia among north Indians. Neuropsychobiology. 2010;61(2):64-70.

5. Lee SH, DeCandia TR, Ripke S, et al. Estimating the proportion of variation in susceptibility to schizophrenia captured by common SNPs. Nat Genet. 2012;44(3):247-250.

6. Lee SH, Ripke S, Neale BM, et al. Genetic relationship between five psychiatric disorders estimated from genome-wide SNPs. Nat Genet. 2013;45(9):984-994.

7. Mehta D, Tropf FC, Gratten J, et al. Evidence for genetic overlap between schizophrenia and age at first birth in women. JAMA Psychiatry. 2016;73(5):497-505.

8. Purcell SM, Wray NR, Stone JL, et al. Common polygenic variation contributes to risk of schizophrenia and bipolar disorder. Nature. 2009; 460(7256):748-752.

9. Arinami T, Itokawa M, Enguchi $\mathrm{H}$, et al. Association of dopamine D2 receptor molecular variant with schizophrenia. Lancet. 1994; 343(8899):703-704.

10. Lawford BR, Young RM, Swagell CD, et al. The C/C genotype of the C957T polymorphism of the dopamine D2 receptor is associated with schizophrenia. Schizophr Res. 2005;73(1):31-37.

11. Behravan J, Hemayatkar M, Toufani H, Abdollahian E. Linkage and association of DRD2 gene TaqI polymorphism with schizophrenia in an Iranian population. Arch Iran Med. 2008;11(3):252-256.

12. Yao J, Pan YQ, Ding M, Pang H, Wang BJ. Association between DRD2 (rs1799732 and rs1801028) and ANKK1 (rs1800497) polymorphisms and schizophrenia: a meta-analysis. Am J Med Genet B Neuropsychiatr Genet. 2015;168B(1):1-13.

13. Dubertret C, Bardel C, Ramoz N, et al. A genetic schizophreniasusceptibility region located between the ANKK1 and DRD2 genes. Prog Neuropsychopharmacol Biol Psychiatry. 2010;34(3):492-499.

14. Cordeiro Q, Siqueira-Roberto J, Zung S, Vallada H. Association between the DRD2-141C Insertion/Deletion polymorphism and schizophrenia. Arq Neuropsiquiatr. 2009;67(2A):191-194.

15. Dubertret C, Gouya L, Hanoun N, et al. The 3' region of the DRD2 gene is involved in genetic susceptibility to schizophrenia. Schizophr Res. 2004;67(1):75-85.

16. Cordeiro Q, Vallada H. Association study between the Taq1A (rs1800497) polymorphism and schizophrenia in a Brazilian sample. Arq Neuropsiquiatr. 2014;72(8):582-586.

17. Duan J, Wainwright MS, Comeron JM, et al. Synonymous mutations in the human dopamine receptor D2 (DRD2) affect mRNA stability and synthesis of the receptor. Hum Mol Genet. 2003;12(3):205-216.

18. Zheng CM. The association study and preliminary functional exploration of CCKAR, DRD2, DAT and SNAPIN genes in schizophrenia [dissertation]. Beijing, China: Peking Union Medical College; 2012.

19. Vijayan NN, Bhaskaran S, Koshy LV, et al. Association of dopamine receptor polymorphisms with schizophrenia and antipsychotic response in a South Indian population. Behav Brain Funct. 2007;3:34.

20. Niu YM, Du XY, Cai HX, et al. Increased risks between Interleukin-10 gene polymorphisms and haplotype and head and neck cancer: a metaanalysis. Sci Rep. 2015;5:17149.

21. Lopez-Lopez E, Martin-Guerrero I, Ballesteros J, Garcia-Orad A. A systematic review and meta-analysis of MTHFR polymorphisms in methotrexate toxicity prediction in pediatric acute lymphoblastic leukemia. Pharmacogenomics J. 2013;13(6):498-506.

22. Tsutsumi A, Glatt SJ, Kanazawa T, et al. The genetic validation of heterogeneity in schizophrenia. Behav Brain Funct. 2011;7:43.

23. Aslan S, Karaoguz MY, Eser HY, Karaer DK, Taner E. Comparison of DRD2 rs1800497 (TaqIA) polymorphism between schizophrenic patients and healthy controls: lack of association in a Turkish sample. Int J Psychiat Clin. 2010;14(4):257-261.

24. Luo PF. Association of dopamine D2 receptor polymorphisms with paranoid schizophrenia in the North Chinese population [dissertation]. Beijing, China: Peking Union Medical College; 2008.

25. Parsons MJ, Mata I, Beperet M, et al. A dopamine D2 receptor generelated polymorphism is associated with schizophrenia in a Spanish population isolate. Psychiatr Genet. 2007;17(3):159-163. 
26. Sasaki T, Macciardi FM, Badri F, et al. No evidence for association of dopamine D2 receptor variant (Ser311/Cys311) with major psychosis. Am J Med Genet. 1996;67(4):415-417.

27. Hattori M, Nanko S, Dai XY, Fukuda R, Kazamatsuri H. Mismatch PCR RFLP detection of DRD2 Ser311Cys polymorphism and schizophrenia. Biochem Biophys Res Commun. 1994;202(2):757-763.

28. Caprini S, Saetre P, Melle I, et al. Lack of association between two dopamine D2 receptor gene polymorphisms and schizophrenia. Psychiatr Genet. 2011;21(4):214-215.

29. Shaikh S, Collier D, Arranz M, Ball D, Gill M, Kerwin R. DRD2 Ser311/ Cys311 polymorphism in schizophrenia. Lancet. 1994;343(8904): 1045-1046.

30. Sobell J, Sigurdson DC, Heston L, Sommer S. S311C D2DR variant: no association with schizophrenia. Lancet. 1994;344(8922):621-622.

31. Crawford F, Hoyne J, Cai X, et al. Dopamine DRD2/Cys311 is not associated with chronic schizophrenia. Am J Med Genet. 1996;67(5): 483-484.

32. Schizophrenia Working Group of the Psychiatric Genomics Consortium. Biological insights from 108 schizophrenia-associated genetic loci. Nature. 2014;511(7510):421-427.

33. Liu ZW, Liu JL, An Y, Zhang L, Wang YM. Association between Ser311Cys polymorphism in the dopamine D2 receptor gene and schizophrenia risk: a meta-analysis in Asian populations. Genet Mol Res. 2012;11(1):261-270.

34. Nothen MM, Korner J, Lannfelt L, et al. Lack of association between schizophrenia and alleles of the dopamine D1, D2, D3 and D4 receptor loci. Psychiat Genet. 1993;3(2):89-94.

35. Dollfus S, Campion D, Vasse T, et al. Association study between dopamine D1, D2, D3, and D4 receptor genes and schizophrenia defined by several diagnostic systems. Biol Psychiatry. 1996;40(5):419-421.

36. Watanabe Y, Nunokawa A, Kaneko N, et al. Case-control study and meta-analysis of Ser311Cys polymorphism in the DRD2 gene demonstrate lack of association with risk for schizophrenia in the Japanese population. Genet Mol Res. 2012;11(2):1142-1145.

37. Himei A, Koh J, Sakai J, et al. The influence on the schizophrenic symptoms by the DRD2Ser/Cys311 and -141C Ins/Del polymorphisms. Psychiatry Clin Neurosci. 2002;56(1):97-102.

38. Chen $\mathrm{CH}$, Chien SH, Hwu HG. No association of dopamine D2 receptor molecular variant Cys311 and schizophrenia in Chinese patients. Am J Med Genet. 1996;67(4):418-420.

39. Fan H, Zhang F, Xu Y, et al. An association study of DRD2 gene polymorphisms with schizophrenia in a Chinese Han population. Neurosci Lett. 2010;477(2):53-56.

40. Golimbet VE, Lebedeva IS, Monakhov MV, et al. The cys allele (the Ser311Cys polymorphism) of the dopamine $\mathrm{d} 2$ receptor is associated with schizophrenia and impairments to selective attention in patients. Neuroscience and Behavioral Physiology. 2011;41(1):22-24.

41. Gupta M, Chauhan C, Bhatnagar P, et al. Genetic susceptibility to schizophrenia: role of dopaminergic pathway gene polymorphisms. Pharmacogenomics. 2009;10(2):277-291.

42. Harano M. Ser-311-Cys polymorphism of the dopamine D2 receptor gene and schizophrenia--an analysis of schizophrenic patients in Fukuoka. Kurume Med J. 1997;44(3):201-208.

43. Hori H, Ohmori O, Shinkai T, Kojima H, Nakamura J. Association analysis between two functional dopamine D2 receptor gene polymorphisms and schizophrenia. Am J Med Genet. 2001;105(2): 176-178.

44. Iwata Y, Matsumoto H, Minabe Y, et al. Early-onset schizophrenia and dopamine-related gene polymorphism. Am J Med Genet B Neuropsychiatr Genet. 2003;116B(1):23-26.

45. Jonsson EG, Sillen A, Vares M, et al. Dopamine D2 receptor gene Ser311Cys variant and schizophrenia: association study and metaanalysis. Am J Med Genet B Neuropsychiatr Genet. 2003;119B(1): 28-34.

46. Kaneshima M, Higa T, Nakamoto $H$, Nagamine M. An association study between the Cys311 variant of dopamine D2 receptor gene and schizophrenia in the Okinawan population. Psychiatry Clin Neurosci. 1997;51(6):379-381.
47. Arinami T, Itokawa M, Aoki J, et al. Further association study on dopamine D2 receptor variant $\mathrm{S} 311 \mathrm{C}$ in schizophrenia and affective disorders. Am J Med Genet. 1996;67(2):133-138.

48. Laurent C, Bodeau-Pean S, Campion D, et al. No major role for the dopamine D2 receptor Ser $\rightarrow$ Cys311 mutation in schizophrenia. Psychiat Genet. 1994;4(4):229-230.

49. Sanders AR, Duan J, Levinson DF, et al. No significant association of 14 candidate genes with schizophrenia in a large European ancestry sample: implications for psychiatric genetics. Am J Psychiatry. 2008;165(4): 497-506.

50. Spurlock G, Williams J, McGuffin P, et al. European Multicentre Association Study of Schizophrenia: a study of the DRD2 Ser311Cys and DRD3 Ser9Gly polymorphisms. Am J Med Genet. 1998;81(1):24-28.

51. Tanaka T, Igarashi S, Onodera $\mathrm{O}$, et al. Lack of association between dopamine D2 receptor gene Cys311 variant and schizophrenia. Am J Med Genet. 1996;67(2):208-211.

52. Verga M, Macciardi F, Pedrini S, Cohen S, Smeraldi E. No association of the Ser/Cys311 DRD2 molecular variant with schizophrenia using a classical case control study and the haplotype relative risk. Schizophr Res. 1997;25(2):117-121.

53. Itokawa $\mathrm{M}$, Arinami $\mathrm{T}$, Toru $\mathrm{M}$. Advanced research on dopamine signaling to develop drugs for the treatment of mental disorders: Ser311Cys polymorphisms of the dopamine D2-receptor gene and schizophrenia. J Pharmacol Sci. 2010;114(1):1-5.

54. Fujiwara Y, Yamaguchi K, Tanaka Y, et al. Polymorphism of dopamine receptors and transporter genes in neuropsychiatric diseases. Eur Neurol. 1997;38(Suppl 1):6-10.

55. Morimoto K, Miyatake R, Nakamura M, et al. Delusional disorder: molecular genetic evidence for dopamine psychosis. Neuropsychopharmacol. 2002;26(6):794-801.

56. Fan J, Zhou R, Zhou C, Wang Y, Shen Y. Association of dopamine D2 receptor gene polymorphism with schizophrenia. Journal of Beijing Medical University. 1996;28(1).

57. Arinami T, Gao M, Hamaguchi H, Toru M. A functional polymorphism in the promoter region of the dopamine $\mathrm{D} 2$ receptor gene is associated with schizophrenia. Hum Mol Genet. 1997;6(4):577-582.

58. Itokawa M, Arinami T, Futamura N, Hamaguchi H, Toru M. A structural polymorphism of human dopamine D2 receptor, D2(Ser311->Cys). Biochem Biophys Res Commun. 1993;196(3):1369-1375.

59. Asherson P, Williams N, Roberts E, McGuffin M, Owen M. DRD2 Ser311/Cys311 polymorphism in schizophrenia. Lancet. 1994;343(8904):1045.

60. Nanko S, Hattori M, Dai XY, Fukuda R, Kazamatsuri H. DRD2 Ser311/Cys311 polymorphism in schizophrenia. Lancet. 1994; 343(8904): 1044.

61. Gejman PV, Ram A, Gelernter J, et al. No structural mutation in the dopamine D2 receptor gene in alcoholism or schizophrenia. Analysis using denaturing gradient gel electrophoresis. JAMA. 1994; 271(3):204-208.

62. Kunii Y, Miura I, Matsumoto J, et al. Elevated postmortem striatal t-DARPP expression in schizophrenia and associations with DRD2/ ANKK1 polymorphism. Prog Neuropsychopharmacol Biol Psychiatry. 2014;53:123-128.

63. Breen G, Brown J, Maude S, et al. $-141 \mathrm{C}$ del/ins polymorphism of the dopamine receptor 2 gene is associated with schizophrenia in a British population. Am J Med Genet. 1999;88(4):407-410.

64. Hanninen K, Katila H, Kampman O, et al. Association between the C957T polymorphism of the dopamine D2 receptor gene and schizophrenia. Neurosci Lett. 2006;407(3):195-198.

65. Hoenicka J, Aragues M, Rodriguez-Jimenez R, et al. C957T DRD2 polymorphism is associated with schizophrenia in Spanish patients. Acta Psychiatr Scand. 2006;114(6):435-438.

66. Jonsson EG, Nothen MM, Neidt H, et al. Association between a promoter polymorphism in the dopamine D2 receptor gene and schizophrenia. Schizophr Res. 1999;40(1):31-36.

67. Kurt H, Dikmen M, Basaran A, et al. Dopamine D2 receptor gene-141C Insertion/Deletion polymorphism in Turkish schizophrenic patients. Mol Biol Rep. 2011;38(2):1407-1411. 
68. Lafuente A, Bernardo M, Mas S, et al. -141C Ins/Del polymorphism of the dopamine D2 receptor gene is associated with schizophrenia in a Spanish population. Psychiatr Genet. 2008;18(3):122-127.

69. Monakhov M, Golimbet V, Abramova L, Kaleda V, Karpov V. Association study of three polymorphisms in the dopamine D2 receptor gene and schizophrenia in the Russian population. Schizophr Res. 2008;100(1-3):302-307.

70. Li T, Arranz M, Aitchison KJ, et al. Case-control, haplotype relative risk and transmission disequilibrium analysis of a dopamine D2 receptor functional promoter polymorphism in schizophrenia. Schizophr Res. 1998;32(2):87-92.

71. Ohara K, Nagai M, Tani K, et al. Functional polymorphism of -141C Ins/Del in the dopamine D2 receptor gene promoter and schizophrenia. Psychiatry Res. 1998;81(2):117-123.

72. Saiz PA, Garcia-Portilla MP, Arango C, et al. Genetic polymorphisms in the dopamine-2 receptor (DRD2), dopamine-3 receptor (DRD3), and dopamine transporter (SLC6A3) genes in schizophrenia: Data from an association study. Prog Neuropsychopharmacol Biol Psychiatry. 2010;34(1):26-31.

73. Stöber $\mathrm{G}$, Jatzke $\mathrm{S}$, Heils A, et al. Insertion/deletion variant (-141C $\mathrm{Ins} / \mathrm{Del}$ ) in the 5 ' regulatory region of the dopamine D2 receptor gene: Lack of association with schizophrenia and bipolar affective disorder. J Neural Transm. 1998;105(1):101-109.

74. Tallerico T, Ulpian C, Liu IS. Dopamine D2 receptor promoter polymorphism: no association with schizophrenia. Psychiatry Res. 1999; 85(2):215-219.

75. Kampman O, Anttila S, Illi A, et al. Dopamine receptor D2 -141C Insertion/Deletion polymorphism in a Finnish population with schizophrenia. Psychiat Res. 2003;121(1):89-92.

76. Xiao L, Shen T, Peng DH, et al. Functional -141C Ins/Del polymorphism in the dopamine D2 receptor gene promoter and schizophrenia in a Chinese Han population. J Int Med Res. 2013;41(4):1171-1178.

77. Comings DE, Comings BG, Muhleman D, et al. The dopamine D2 receptor locus as a modifying gene in neuropsychiatric disorders. JAMA. 1991;266(13):1793-1800.
78. Sanders AR, Rincon-Limas DE, Chakraborty R, et al. Association between genetic variation at the porphobilinogen deaminase gene and schizophrenia. Schizophr Res. 1993;8(3):211-221.

79. Campion D, D'Amato T, Bastard C, et al. Genetic study of dopamine D1, D2, and D4 receptors in schizophrenia. Psychiatry Res. 1994; 51(3):215-230.

80. Inada T, Arinami T, Yagi G. Association between a polymorphism in the promoter region of the dopamine D2 receptor gene and schizophrenia in Japanese subjects: replication and evaluation for antipsychotic-related features. Int J Neuropsychopharmacol. 1999;2(3):181-186.

81. Serretti A, Lilli R, Lorenzi C, Smeraldi E. Further evidence supporting the association between the dopamine receptor D2 Ser/Cys311 variant and disorganized symptomatology of schizophrenia. Schizophr Res. 2000;43(2-3):161-162.

82. $\mathrm{LiH}$. Association research among candidate genes, clinical symptoms and cognitive function in schizopjrenia [D]. Jilin: Jilin University. 2014.

83. Liu X, Zhang L, Zhang Y, Wang Y. Association analysis between the prodynorphin gene and the dopamine D2 receptor gene and schizophrenia. Journal of Psychiatry. 2009;22(2):89-93.

84. Shen T, Peng D, Xiao L, et al. Association of a promoter polymorphism in the dopamine receptor $\mathrm{d} 2$ gene in han population with schizophrenia. Medical Journal of Wuhan University. 2011;32(3):354-357.

85. Zhang M, Yuan G, Yao J, et al. Associations between six functional genes and schizophrenia. Chin J Med Genet. 2003;20(1):73-75.

86. Liang K. The association of DA2, DA3, DA4 receptor gene polymorphology with schizophrenia also in medical jurisprudence and human genetics studies [D]. Shenyang: China Medical University. 2005.

87. Jonsson E, Brene S, Geijer T, et al. A search for association between schizophrenia and dopamine-related alleles. Eur Arch Psychiatry Clin Neurosci. 1996;246(6):297-304.
Neuropsychiatric Disease and Treatment

\section{Publish your work in this journal}

Neuropsychiatric Disease and Treatment is an international, peerreviewed journal of clinical therapeutics and pharmacology focusing on concise rapid reporting of clinical or pre-clinical studies on a range of neuropsychiatric and neurological disorders. This journal is indexed on PubMed Central, the 'PsycINFO' database and CAS,

\section{Dovepress}

and is the official journal of The International Neuropsychiatric Association (INA). The manuscript management system is completely online and includes a very quick and fair peer-review system, which is all easy to use. Visit http://www.dovepress.com/testimonials.php to read real quotes from published authors. 


\section{Supplementary material}

Table SI Scale for quality assessment

Criteria

Representativeness of cases

Consecutive/randomly selected form case population with clearly defined sampling frame 2

Consecutive/randomly selected form case population without clearly defined sampling frame or with extensive

Not described

Definition of the DR

Population- or health-based

Hospital-bases

Not described

Hardy-Weinberg equilibrium in controls

Hardy-Weinberg equilibrium

Hardy-Weinberg disequilibrium

Genotyping examination

Genotyping done under "blinded" condition I

Unblinded done or not mentioned 0

Association assessment

Assess association between genotypes and head and neck cancer with appropriate statistics and adjustment for confounders

Assess association between genotypes and head and neck cancer with appropriate statistics and without adjustment for confounders $\quad$ I

Inappropriate statistics used

\section{Publish your work in this journal}

Neuropsychiatric Disease and Treatment is an international, peerreviewed journal of clinical therapeutics and pharmacology focusing on concise rapid reporting of clinical or pre-clinical studies on a range of neuropsychiatric and neurological disorders. This journal is indexed on PubMed Central, the 'PsycINFO' database and CAS, and is the official journal of The International Neuropsychiatric Association (INA). The manuscript management system is completely online and includes a very quick and fair peer-review system, which is all easy to use. Visit http://www.dovepress.com/testimonials.php to read real quotes from published authors.

\footnotetext{
Submit your manuscript here: http://www.dovepress.com/neuropsychiatric-disease-and-treatment-journal
} 